\title{
Significance of plasma lysolecithin in patients with multiple sclerosis : a longitudinal study
}

\author{
V. M. ANDREOLI, F. MAFFEI, G. C. TONON, AND A. ZIBETTI \\ From the Institute of Pharmacology and the Multiple Sclerosis Centre, \\ University of Milan, 20129 Milan, Italy
}

SUMMARY Five patients with multiple sclerosis and four normal subjects have been followed for over two years. Plasma phospholipid levels and phospholipid fatty acid composition have been assayed periodically. The increased amount of plasma lysolecithin already described by us has been confirmed in this longitudinal study. A significant increase in saturated fatty acids of lysolecithin has also been demonstrated. In contrast, the lecithin concentration and fatty acid composition do not show any significant variations. The lysolecithin saturated/unsaturated fatty acid ratio was different in the same patients at different times, but no correlation was established between these variations and the clinical symptoms measured using the Kurtzke scale. The possible significance of saturated fatty acid increase in lysolecithin in the pathogenetic mechanisms of multiple sclerosis is discussed.

A definite increase $(77 \%)$ in plasma lysolecithin levels has been reported by Andreoli and Cazzullo (1969) in patients affected by multiple sclerosis (MS) in its active stages as compared with normal subjects. The fatty acid composition of plasma lecithin was also modified. In contrast, no changes were observed in platelet phospholipids and the platelet lecithin-lysolecithin ratio was unchanged in the same patients (Andreoli and Cazzullo, 1968).

These findings support the hypothesis that a plasma factor, possibly related to changes in the saturated-unsaturated fatty acid ratio of lecithins and/or lysolecithins, may be responsible for the well-known changes in platelet behaviour (Shore and Alpers, 1963; Caspary, Prineas, Miller, and Field, 1965; Wright, Thompson, and Zilka, 1965; Thompson, 1966), and in the formation of microthrombi (Putnam, 1935; Kerr, Pirrie, MacAulay, and Bronte-Stewart, 1965) in MS patients. The lipid changes should therefore be studied over a long period of time in the same subjects.

For this reason, the present investigation has been designed in order to observe selected patients for up to two years and to point out possible correlations between changes in blood lipids and the onset of the acute phases of the disease.

\section{METHODS}

SELECTION OF PATIENTS Five MS patients of both sexes, aged between 30 and 50 years, and four normal subjects in the same age group were selected and followed during periods of time lasting between six months and two years. Normal subjects had no clinical or biological defects and they did not present any illness during the observation period. All patients were selected at the Multiple Sclerosis Centre of the University of Milan, while at the Centre for a sudden deterioration of the clinical symptoms. They had not received any drugs for at least two months before selection.

Another criterion in our selection was the presence of exacerbations of the disease in the previous history of the patients; in this way, all the familial forms, progressive and slowly emerging, were discarded. At the time of selection and during the observation period each patient was graded by the method of Kurtzke (1961).

Blood samples were withdrawn and serum globulins, immunoglobulins, lipids, and the fatty acids in the individual phospholipid fractions were measured. 661 
The selected patients were kept in the clinical ward for 40 days and were later checked in the outpatients' department every 30 days regularly. At various time intervals after the clinical examination, blood samples were obtained, when possible in relation to the onset of a new relapse.

METHODS OF CHEMICAL ANALYSIS Blood samples $(80-100 \mathrm{ml}$.) were mixed $(1: 10 \mathrm{v} / \mathrm{v})$ with EDTA $1 \%$ (Analar, B.D.H. Company) and were immediately centrifuged at $4^{\circ} \mathrm{C}$ at $3,000 \mathrm{rpm}$ for 10 minutes.
Immunoglobulins were determined by the method of Mancini, Vaerman, Carbonara, and Heremans (1964). Plasma lipids were extracted from $2 \mathrm{ml}$. plasma mixed with $25 \mathrm{ml} .0 \cdot 94 \% \mathrm{NaCl}$ in a separation funnel. Cold methanol $(30 \mathrm{ml}$.) was added very slowly and the resulting solution was mixed very thoroughly for five minutes. Finally, $30 \mathrm{ml}$. chloroform were added, the solvents mixed, and the funnel flushed with nitrogen and left overnight in the cold to allow separation in two phases. On the following day the chloroform layer was evaporated in a rotary
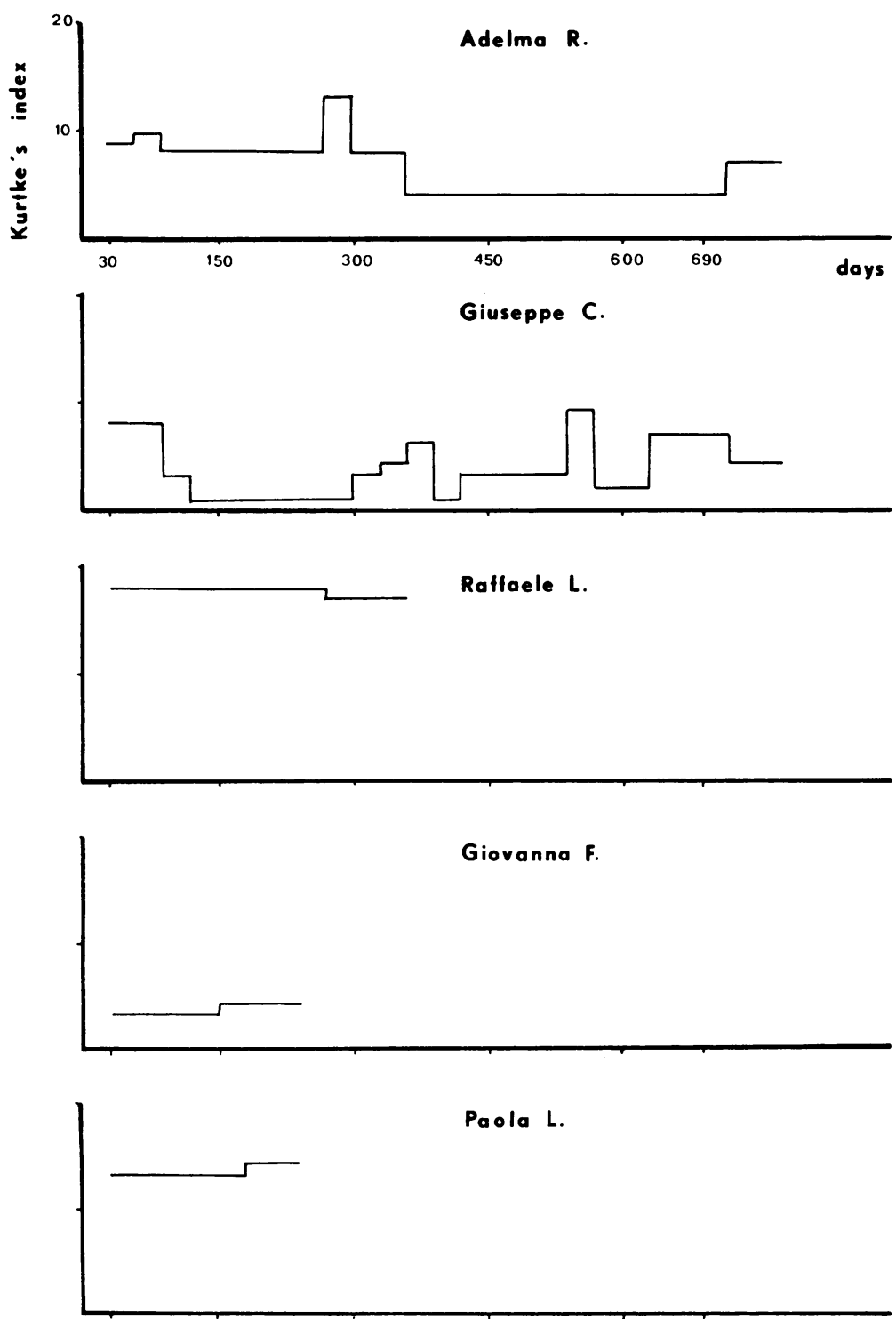

FIG. 1. Clinical evolution of multiple sclerosis patients according to the Kurtzke rating scale. Adelma $R$., female, 29 years, spinocerebellar form, duration of disease: six years.

Giuseppe, C., male, 32 years, spinal form, duration of disease: 13 years.

Raffaele L., male, 34 years, spinal form, duration of disease: seven years.

Giovanna $F$., female, 30 years, spinal form, duration of disease: one year.

Paola L., female, 51 years, spinal form, duration of disease: 30 years. 
evaporator (Rotavapor-R, Büchi). The lipids dissolved in a known volume of chloroform-methanol $(2: 1 \mathrm{v} / \mathrm{v})$ were then analysed using two-dimensional thin-layer chromatography (TLC) on silica gel $\mathbf{H}$ (no binder) (Merck Company) and magnesium silicate (Merck Company) (90/10), slurried in $0.01 \mathrm{~N} \mathrm{KOH,}$ in layers of $0.25 \mathrm{~mm}$ thickness.

For analysis of neutral lipids the solvent system used was in the first dimension chloroform/methanol/ ammonia ( $95 / 5 / 0.8$ by vol.) and in the second hexane/ diethylether/acetic acid (80/20/4 by vol.).

For analysis of phospholipids the solvent mixture for the first run was chloroform/methanol/ammonia $(65 / 35 / 5$ by vol.) and for the second chloroform/ acetone/methanol/acetic acid/water $(5 / 2 / 1 / 1 / 0 \cdot 5$ by vol.), following the general procedure described by Rouser, Galli, Lieber, Blank, and Privett (1964), Rouser, Kritchevsky, Galli, and Heller (1965). The lipid spots were detected after spraying with formaldehyde $3 \%(\mathrm{w} / \mathrm{v})$ in a sulphuric acid solution and charring at $180^{\circ} \mathrm{C}$ for 30 minutes. The chromatographic spots were individually collected into testtubes and the phosphorus content, without elution of the sample from the adsorbent, was determined according to Rouser, Siakotos, and Fleischer (1966).

The lysolecithin fraction considered significant for the investigation was separated by chromatography on DEAE columns reactivated by acetic acid, then washed with methanol and chloroform. The samples, in chloroform, were added to the column and the fractions collected after addition of: (1) chloroform (five column volumes) for the separation of cholesterol, cholesterol esters, triglycerides; (2) chloroformmethanol $(9 / 1, v / v)$ (nine column volumes) for lecithin, lysolecithin, sphingomyelin; (3) chloroformmethanol $(2 / 1, \mathrm{v} / \mathrm{v}), 1 \% \mathrm{w} / \mathrm{v}$ acetic acid $(12$ column volumes) containing phosphatidyl-ethanolamine and free fatty acids (FFA). Lecithin and lysolecithin were separated on monodimensional thin layer chromatography using the system chloroform/methanol/ water (60/40/5 by vol.). The recovery after extraction and chromatography was about $98 \%$.

The different phospholipid molecular species after chromatographic separation based on a combination of DEAE column and thin-layer chromatography were collected after scraping from the thin-layer chromatograms. Methyl-esters of the fatty acids of lecithin and lysolecithin were prepared by adding $2 \mathrm{ml} .6 \%$ (w/v) $\mathrm{H}_{2} \mathrm{SO}_{4}$ in methanol directly to the silica gel and sealing the tubes under nitrogen and heating at $110^{\circ} \mathrm{C}$ overnight, according to the method of Feldman and Rouser (1965).

In some experiments the fatty acid mixtures were subdivided according to the number of double bonds, using TLC of the methoxybromomercury adducts (White and Powell, 1968).

The methyl-esters of fatty acids, extracted with hexane, purified by TLC (hexane/ethyl ether/acetic acid, $85 / 15 / 2$ by vol.) and displayed with $I_{2}$, were then separated on polar (DEGS) columns at programmed temperature (column temperature: $200^{\circ} \mathrm{C}$, flash heater zone: $300^{\circ} \mathrm{C}$, detector: $325^{\circ} \mathrm{C}$ ) using a gas chromatograph (Fractovap Model GV, Carlo Erba) (carrier gas He with a flow rate of $23 \mathrm{ml} . / \mathrm{min}$ ).

The identification of single fatty acids and fatty aldehydes was obtained by measuring the retention times in the GLC system and by comparison with standard mixtures provided by Applied Science Laboratories (State College, Pennsylvania, U.S.A.). The identification of single fatty acids and fatty aldehydes has been carried out further by using a combination of GLC and mass-spectrometry (LKB model 9000) (Capella, Galli, and Fumagalli, 1968).

Platelets were obtained from blood (after addition of $1 \%(\mathrm{w} / \mathrm{v})$ EDTA) by rapid centrifugation in siliconized tubes at $4^{\circ} \mathrm{C}$ at $600 \mathrm{rpm}$ for 60 minutes. The platelet-rich plasma was then centrifuged at $4^{\circ} \mathrm{C}$ at 2,500 rpm for 20 minutes. Platelet pellets were resuspended and washed three times with isotonic saline solution. Platelet lipids were extracted with

TABLE 1

PERCENTAGE COMPOSITION OF SINGLE PLASMA-PHOSPHOLIPID FRACTIONS IN NORMAL SUBJECTS AND MS PATIENTS

\begin{tabular}{|c|c|c|c|c|}
\hline \multirow[t]{2}{*}{ Phospholipid fraction } & \multicolumn{2}{|c|}{ Mean values and fiducial limits } & \multirow{2}{*}{$\begin{array}{l}\text { Variance } \\
\text { analysis } \\
(F)\end{array}$} & \multirow{2}{*}{$\begin{array}{c}\text { Significance } \\
\text { levels } \\
(P)\end{array}$} \\
\hline & $\begin{array}{c}\text { Normal subjects } \\
(\%)\end{array}$ & $\begin{array}{c}M S \text { patients } \\
(\%)\end{array}$ & & \\
\hline Sphingomyelin & $20 \cdot 48 \pm 1 \cdot 73(11)$ & $20 \cdot 60 \pm 1 \cdot 9 i(25)$ & - & NS \\
\hline Lecithin & $67 \cdot 81 \pm 1 \cdot 30(11)$ & $65.45 \pm 2.04(25)$ & $4 \cdot 70$ & NS \\
\hline Phosphatidylethanolamine & $2.53 \pm 1.00(11)$ & $3 \cdot 13 \pm 1 \cdot 23(25)$ & 2.61 & NS \\
\hline Phosphatidylinositol & $1.67 \pm 1.21(11)$ & $1.77 \pm 0.93(25)$ & $1 \cdot 16$ & NS \\
\hline Lysolecithin & $4.95 \pm 0.62(11)$ & $7.84 \pm 1.06(25)$ & $18 \cdot 75$ & $P<0.01$ \\
\hline
\end{tabular}

In parentheses the number of determinations.

Four normal subjects and five MS patients were involved. 
TABLE 2

VARIATION IN PLASMA LYSOLECITHIN IN NORMAL SUBJECTS AND MS PATIENTS AT VARIOUS INTERVALS

\begin{tabular}{|c|c|c|c|c|c|c|c|c|c|}
\hline \multirow{2}{*}{$\begin{array}{c}\text { Observation } \\
\text { times } \\
\text { (months) }\end{array}$} & \multicolumn{4}{|c|}{ Normal subjects (4) } & \multicolumn{5}{|c|}{ MS patients (5) } \\
\hline & S.I. & G.S. & P.A. & F.S. & A.R. & G.C. & R.L. & G.F. & P.L. \\
\hline 1st & 4.01 & $4 \cdot 85$ & 4.43 & 4.46 & 5.41 & 6.99 & 6.85 & $9 \cdot 15$ & $5 \cdot 70$ \\
\hline 2nd & & & & & $7 \cdot 26$ & & 8.97 & $5 \cdot 03$ & 7.05 \\
\hline $3 \mathrm{rd}$ & $5 \cdot 31$ & 5.55 & & & 5.06 & 8.96 & 8.50 & & 7.66 \\
\hline 4th & $5 \cdot 11$ & 5.59 & & & $5 \cdot 82$ & 6.99 & 3.61 & & $5 \cdot 77$ \\
\hline 5th & & & & & $6 \cdot 26$ & 7.61 & & & \\
\hline 6th & & & & $4 \cdot 36$ & & & & & $7 \cdot 84$ \\
\hline 9th & $5 \cdot 68$ & & & & 5.87 & & 7.99 & & \\
\hline $\begin{array}{l}\text { 10th } \\
\text { 11th }\end{array}$ & & & $5 \cdot 35$ & & & $\begin{array}{r}10 \cdot 61 \\
8.73\end{array}$ & $8 \cdot 08$ & & \\
\hline 11th & & & & & & 8.73 & & & \\
\hline
\end{tabular}

Values are single determinants shown as $\%$ total plasma phospholipid.

chloroform-methanol $(2 / 1 \mathrm{v} / \mathrm{v})$ and were then analysed using the procedures previously described for plasma lipids.

\section{RESULTS}

The clinical evolution according to the Kurtzke rating scale of the selected MS patients is shown

TABLE 3

LYSOLECITHIN FATTY ACID (PERCENTAGE COMPOSITION) IN NORMAL SUBJECTS

\begin{tabular}{|c|c|c|c|c|c|c|}
\hline & \multicolumn{6}{|c|}{ Observation times (months) } \\
\hline & Ist & $3 r d$ & $4 t h$ & $9 t h$ & $21 s t$ & 23rd \\
\hline \multicolumn{7}{|l|}{ Sebastiana I } \\
\hline C 16:0 & $41 \cdot 31$ & $46 \cdot 64$ & $32 \cdot 75$ & $29 \cdot 24$ & $46 \cdot 81$ & \\
\hline C $16: 1$ & $2 \cdot 42$ & 1.49 & $1 \cdot 11$ & 2.06 & 1.95 & \\
\hline C $17: 0$ & $1 \cdot 54$ & 1.00 & 4.60 & 0.84 & 0.91 & \\
\hline C 18:0 & $23 \cdot 21$ & $20 \cdot 30$ & $19 \cdot 08$ & $14 \cdot 18$ & $21 \cdot 35$ & \\
\hline C 18:1 & $7 \cdot 68$ & $9 \cdot 56$ & $4 \cdot 78$ & $8 \cdot 21$ & $14 \cdot 68$ & \\
\hline C 18:2 & 8.73 & $10 \cdot 52$ & $6 \cdot 15$ & $17 \cdot 21$ & $5 \cdot 75$ & \\
\hline C 20:0 & 0.71 & 0.38 & 0.53 & $5 \cdot 37$ & 0.22 & \\
\hline C $18: 3+$ C $20: 1$ & 0.81 & 0.57 & 4.82 & $3 \cdot 21$ & 0.84 & \\
\hline C 20:2 & $1 \cdot 23$ & 1.07 & 2.57 & 6.51 & 0.65 & \\
\hline C $20: 3+$ C $22: 0$ & 1.59 & 1.52 & 6.72 & 3.96 & 1.95 & \\
\hline C 20:4 & 3.44 & $2 \cdot 38$ & $16 \cdot 70$ & 5.92 & 3.91 & \\
\hline C $22: 2+$ C $20: 5$ & 3.95 & $2 \cdot 00$ & tr. & 1.42 & 0.56 & \\
\hline Unknown & $1 \cdot 55$ & $1 \cdot 08$ & 0.98 & $1 \cdot 27$ & $0 \cdot 36$ & \\
\hline \multicolumn{7}{|l|}{ Gabriella $S$} \\
\hline C 16:0 & $38 \cdot 80$ & $47 \cdot 43$ & $48 \cdot 86$ & & $41 \cdot 70$ & $51 \cdot 79$ \\
\hline C 16:1 & 0.95 & $1 \cdot 26$ & 1.87 & & 0.98 & $2 \cdot 81$ \\
\hline C $17: 0$ & 0.63 & 1.08 & $2 \cdot 18$ & & 0.53 & $0 \cdot 10$ \\
\hline C $18: 0$ & 18.63 & $20 \cdot 12$ & $19 \cdot 29$ & & 19.85 & $15 \cdot 48$ \\
\hline C 18:1 & $14 \cdot 71$ & $13 \cdot 66$ & $12 \cdot 32$ & & $15 \cdot 12$ & $11 \cdot 11$ \\
\hline C 18:2 & 5.92 & $5 \cdot 53$ & $4 \cdot 18$ & & 11.83 & $9 \cdot 64$ \\
\hline C 20:0 & 0.42 & 1.85 & $1 \cdot 30$ & & tr. & 0.29 \\
\hline C $18: 3+$ C $20: 1$ & $0 \cdot 33$ & 0.63 & $0 \cdot 37$ & & $0 \cdot 12$ & $0 \cdot 36$ \\
\hline C 20:2 & $3 \cdot 29$ & 1.53 & 1.25 & & $0 \cdot 18$ & 0.29 \\
\hline C $20: 3+$ C $22: 0$ & $2 \cdot 12$ & 1.69 & 0.82 & & $3 \cdot 23$ & $2 \cdot 26$ \\
\hline C $20: 4$ & $2 \cdot 34$ & $2 \cdot 24$ & $1 \cdot 31$ & & 4.98 & 3.83 \\
\hline C $22: 2+$ C $20: 5$ & 5.73 & 0.95 & $2 \cdot 62$ & & $0 \cdot 30$ & 0.49 \\
\hline Unknown & $3 \cdot 23$ & 1.59 & 1.99 & & $0 \cdot 82$ & 1.64 \\
\hline
\end{tabular}

The results are expressed as percentage of total fatty acids. in Fig. 1; several exacerbations appeared during the observation periods.

Table 1 shows the percentage composition of the single plasma phospholipid fractions in normal subjects and MS patients. The phospholipid determinations were carried out in all subjects during the period of one year. Among plasma. lipids, sphingomyelin, lecithin, phosphatidyl ethanolamine, and phosphatidylinositol reveale $\mathbb{f}_{\mathrm{f}}$ no significant differences in either of the two groups, whereas the lysolecithin fraction showed a significant increase. The variance analysis of the highest values of lysolecithin between normat subjects and MS patients showed a significan increase $(\mathrm{P}<0.01)$. Analytical data on plasma lysolecithin only, from single subjects, are reported in Table 2 . These data clearly indicate a considerable constancy of values for plasma lysolecithin in the normal subjects over extended periods of time.

The variance analysis of the lowest values of lecithin between the two groups revealed no significant decrease $(P<0 \cdot 1)$, because the lecithin fluctuations were also present in normal subjects.

No differences were observed in the platelet lipid composition between normal subjects and MS patients during the same observation periods, in agreement with the previous findings by Andreoli and Cazzullo (1968, 1969).

Tables 3 and 4 show the percentage composition of plasma lysolecithin fatty acids in two normal subjects and three MS patients, at different times during two years of observation. The data indicate a fairly constant fatty acid composition for each subject during prolonged periods of observation. The fatty acid patterns of lyso- 
TABLE 4

LYSOLECITHIN FATTY ACID (PERCENTAGE COMPOSITION) IN MULTIPLE SCLEROSIS PATIENTS

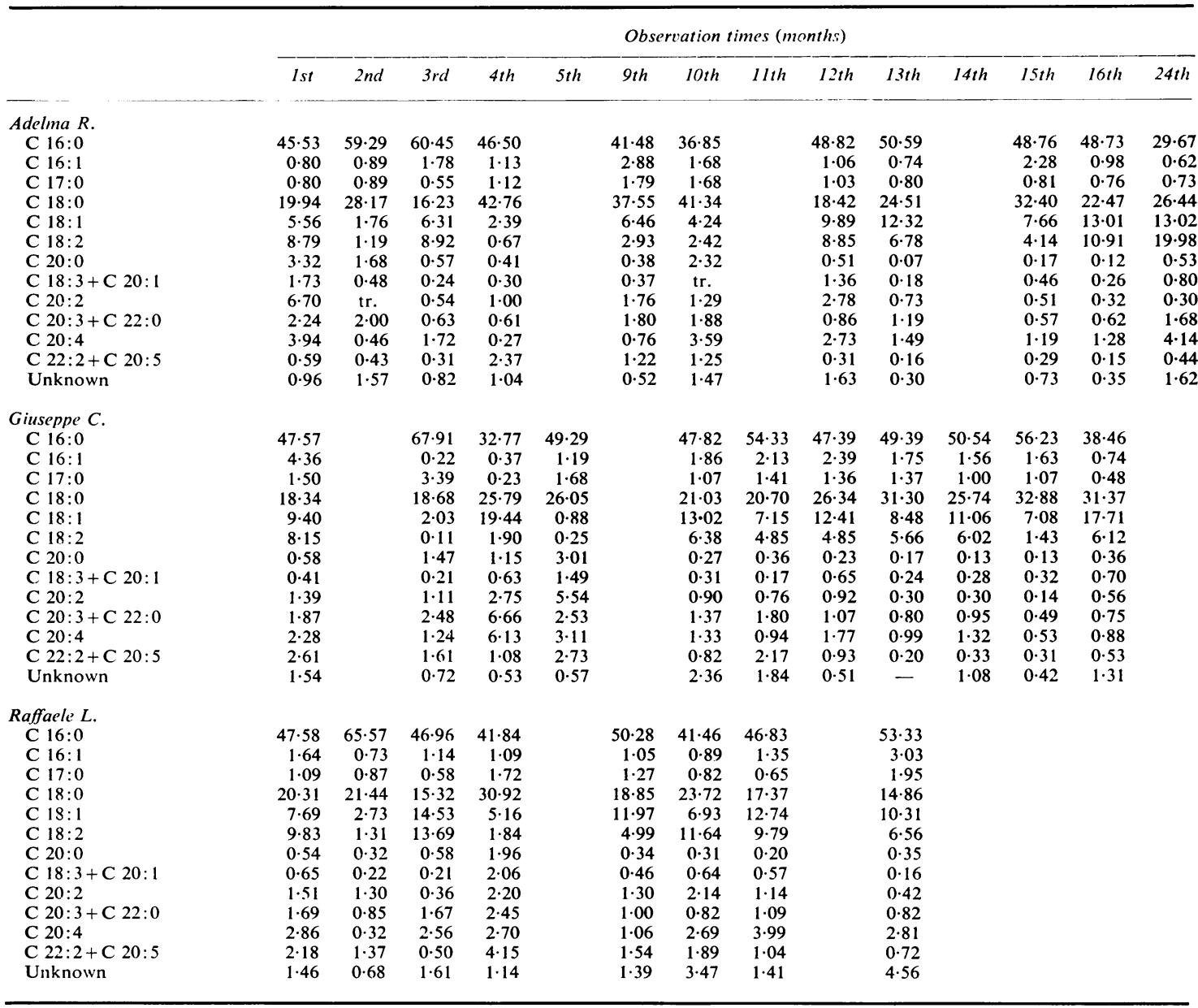

lecithin change in a significant way and some of the modifications are extremely pronounced, whereas fatty acid patterns of lecithin are constant.

Figure 2 shows the ratio between saturated and unsaturated fatty acids of lecithin and lysolecithin from MS patients during two years of observation as related to the normal range.

The ratio between saturated and unsaturated lysolecithin fatty acids and the one between C $16: 0+\mathrm{C} 18: 0$ and $\mathrm{C} 16: 1+\mathrm{C} 18: 1+\mathrm{C} 18: 2$ fatty acids from normal subjects and MS patients, reported at different times, are shown in Table 5. It may be observed that $\mathrm{C} 16+\mathrm{C} 18$ fatty acid values give a sufficiently accurate picture of total fatty acid changes in the lysolecithin fraction. Variance analysis of the greatest values between normal subjects and MS patients of saturated/ unsaturated fatty acid ratios showed statistically significant increase $(P<0.01)$ in $M S$ patients. Nevertheless, covariance analysis revealed that the lysolecithin ratio saturated/unsaturated is not statistically related to the variation of the clinical symptoms as evaluated according to the Kurtzke rating scale. No correlation was observed with the clinical attacks of the disease $(r=0.489$ for significance levels between 0.878 and 0.958 ). During the same period of time, the serum im- 
TABLE 5

RATIO BETWEEN SATURATED AND UNSATURATED LYSOLECITHIN FATTY ACIDS FROM NORMAL SUBJECTS AND MS PATIENTS AT VARIOUS INTERVALS

\begin{tabular}{|c|c|c|c|c|c|c|c|c|c|c|c|c|c|c|c|c|c|c|}
\hline \multirow{3}{*}{$\begin{array}{c}\text { Observation } \\
\text { times } \\
\text { (months) }\end{array}$} & \multicolumn{9}{|c|}{$\frac{\sum \text { Saturated }}{\sum \text { Unsaturated }}$} & \multicolumn{9}{|c|}{$\frac{C 16: 0+C 18: 0}{C 16: 1+C 18: 1+C 18: 2}$} \\
\hline & \multicolumn{4}{|c|}{ Normal subjects (4) } & \multicolumn{5}{|c|}{$M S$ patients $(5)$} & \multicolumn{4}{|c|}{ Normal subjects (4) } & \multicolumn{5}{|c|}{$M S$ patients $(5)$} \\
\hline & S.I. & G.S. & $P . A$. & F.S. & A.R. & G.C. & R.L. & G.F. & P.L. & S.I. & $G . S$. & P.A. & F.S. & A.R. & G.C. & R.L. & $G . F$. & P.L \\
\hline $\begin{array}{l}\text { 1st } \\
\text { 2nd }\end{array}$ & $2 \cdot 00$ & $1 \cdot 40$ & 0.66 & $3 \cdot 50$ & $\begin{array}{r}2 \cdot 28 \\
10 \cdot 00\end{array}$ & $2 \cdot 30$ & $\begin{array}{r}2.60 \\
10 \cdot 00\end{array}$ & $\begin{array}{l}2 \cdot 10 \\
3 \cdot 43\end{array}$ & $4 \cdot 87$ & $3 \cdot 43$ & $2 \cdot 66$ & $0 \cdot 70$ & $4 \cdot 29$ & $\begin{array}{r}4 \cdot 32 \\
22 \cdot 77\end{array}$ & $3 \cdot 12$ & $\begin{array}{r}3 \cdot 74 \\
18 \cdot 35\end{array}$ & $\begin{array}{r}4 \cdot 18 \\
12 \cdot 11\end{array}$ & $6 \cdot 23$ \\
\hline 3rd & $2 \cdot 20$ & $2 \cdot 50$ & & & $3 \cdot 70$ & 12.90 & 1.80 & & & $3 \cdot 10$ & $3 \cdot 30$ & & & 4.51 & 36.69 & $2 \cdot 12$ & & \\
\hline $\begin{array}{l}4 \text { th } \\
5 \text { th }\end{array}$ & $1 \cdot 30$ & $2 \cdot 65$ & & & $10 \cdot 30$ & $\begin{array}{l}1.60 \\
3.20\end{array}$ & 3.60 & $\begin{array}{l}8.55 \\
5.79\end{array}$ & & $4 \cdot 30$ & $3 \cdot 71$ & & & 18.86 & $\begin{array}{r}2.69 \\
32.47\end{array}$ & 8.99 & $\begin{array}{l}7 \cdot 79 \\
7 \cdot 04\end{array}$ & \\
\hline 6 th & & & & $3 \cdot 33$ & & & & & $5 \cdot 22$ & & & & 5.07 & & & & & 6.41 \\
\hline 7 th & & & & & & & & $2 \cdot 61$ & & & & & & & & & $3 \cdot 13$ & \\
\hline 9th & 1.03 & & & & $4 \cdot 70$ & & $2 \cdot 80$ & & & $1 \cdot 58$ & & & & $6 \cdot 24$ & & $3 \cdot 38$ & & \\
\hline 10 th & & & & & 3.81 & $2 \cdot 60$ & $2 \cdot 10$ & & & & & & & $9 \cdot 01$ & $3 \cdot 24$ & $3 \cdot 35$ & & \\
\hline 11 th & & & & & & 3.90 & $2 \cdot 01$ & & & & & & & & $5 \cdot 31$ & $2 \cdot 76$ & & \\
\hline $12 \mathrm{th}$ & & & $2 \cdot 19$ & & $2 \cdot 50$ & $3 \cdot 30$ & & & & & & $2 \cdot 93$ & & $3 \cdot 39$ & $3 \cdot 72$ & & & \\
\hline $14 \mathrm{th}$ & & & & & & 3.42 & & & & & & & & & $4 \cdot 27$ & & & \\
\hline 15 th & & & & & $4 \cdot 59$ & $9 \cdot 32$ & & & & & & & & $5 \cdot 76$ & $8 \cdot 79$ & & & \\
\hline $16 \mathrm{th}$ & & & & & $4 \cdot 58$ & $2 \cdot 38$ & & & & & & & & $2 \cdot 86$ & $2 \cdot 84$ & & & \\
\hline $\begin{array}{l}21 \mathrm{st} \\
22 \mathrm{nd}\end{array}$ & $2 \cdot 23$ & $\begin{array}{l}1.64 \\
2.09\end{array}$ & & & & & & & & 3.04 & $\begin{array}{l}2 \cdot 21 \\
2 \cdot 89\end{array}$ & & & & & & & \\
\hline 24 th & & & & & $1 \cdot 34$ & & & & & & & & & 1.67 & & & & \\
\hline
\end{tabular}

The values for each subject corresponding to the greatest Kurtzke index are italicized.
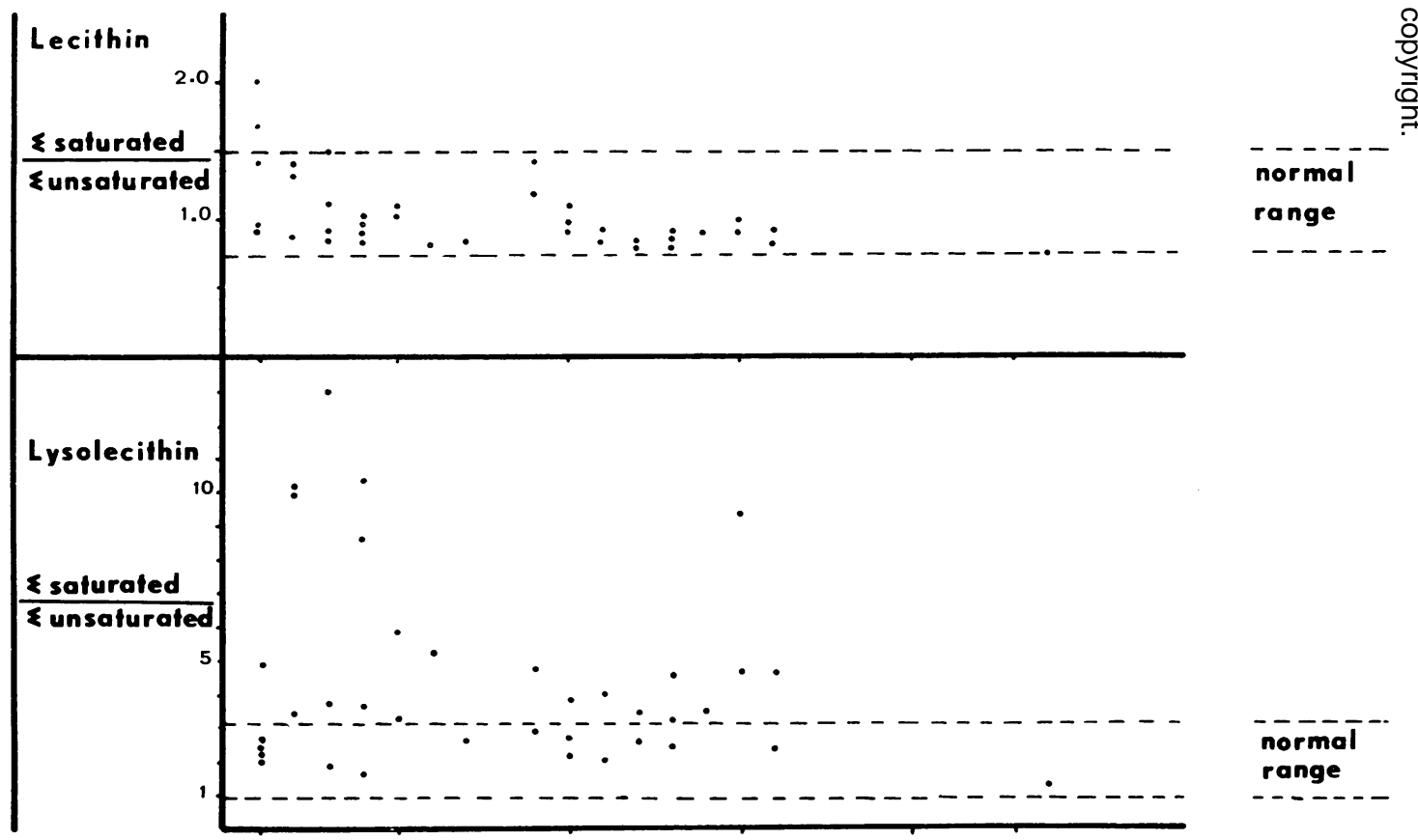

FIG. 2. Ratio between saturated and unsaturated fatty acids of lethicin and lysolecithin from MS patients (five) during two years of observation. 
munoglobulin variations had no significant relationship to the Kurtzke values, either in the four normal subjects or the five MS patients.

\section{DISCUSSION}

The fatty acid patterns of lecithin and lysolecithin in normal subjects showed no significant variations during the periods considered. On the contrary, the concentration of plasma lysolecithins, but not lecithins, was significantly increased in MS patients and their fatty acid patterns changed in a significant way; more particularly, there was an increase of saturated fatty acids in lysolecithins. The increase in concentration of thelysolecithin fraction and its saturated fatty acids may explain the well-known changes in platelet behaviour in MS patients (Shore and Alpers, 1963; Caspary et al., 1965; Wright et al., 1965) and the correlation of multiple sclerosis epidemiology with diets and with other diseases such as atherosclerosis (McAlpine, Lumsden, and Acheson, 1965). Therefore, the observed modifications could be very important in the pathogenetic mechanisms of multiple sclerosis.

The changes observed in fatty acid composition of plasma lysolecithins are probably related to a modification in the lecithin-lysolecithin and free cholesterol-esterified cholesterol systems.

Andreoli, Maffei, Arienti, Tonon, Cazzullo, Montanini, Zibetti, and Smeraldi (1973) have observed that the enzyme lecithin-cholesterol acyltransferase is significantly activated in plasma of MS patients, particularly during the periods of rapid evolution of the disease. However, plasma lysolecithin fatty acid variations do not show a direct correlation with age, sex, degree of disability, duration of the disease, or evolution of multiple sclerosis. No correlation is present with the clinical attacks of the disease, as evaluated by the Kurtzke rating scale. The possibility exists that the Kurtzke index is not sufficiently selective to detect fine biochemical correlations. The plasma lipid modifications may represent a more direct evaluation of the evolution of the disease patterns than a list of very diversified clinical symptoms, such as is the Kurtzke scale.

\section{REFERENCES}

Andreoli, V. M., and Cazzullo, C. L. (1968). Platelet behaviour in multiple sclerosis. Lancet, 1, 528-529.

Andreoli, V. M., and Cazzullo, C. L. (1969). Plasma and platelet phospholipids in multiple sclerosis patients. Life Sciences, 8, Part 2, 327-334.

Andreoli, V. M., Maffei, F., Arienti, G., Tonon, G. C., Cazzullo, C. L., Montanini, R., Zibetti, A., and Smeraldi, E. (1973). Increased lecithin-cholesterol acyltransferase activity in multiple sclerosis patients. Pharmacological Research Communications, 5, 37.

Capella, P., Galli, C., and Fumagalli, R. (1968). Hydroxy fatty acids from cerebrosides of the central nervous system: GLC determination and mass spectrometric identification. Lipids, 3, 431-438.

Caspary, E. A., Prineas, J., Miller, H., and Field, E. J. (1965). Platelet stickiness in multiple sclerosis. Lancet, 2, 11081109.

Feldman, G. L., and Rouser, G. (1965). Ultramicro fatty acid analysis of polar lipids: gas-liquid chromatography after column and thin-layer chromatographic separation. Journal of the American Oil Chemists' Society, 42, 290-293.

Kerr, J. W., Pirrie, R., MacAulay, I., and Bronte-Stewart, B. (1965). Platelet-aggregation by phospholipids and free fatty acids. Lancet, 1, 1296-1299.

Kurtzke, J. F. (1961). On the evaluation of disability in multiple sclerosis. Neurology, (Minneap.), 11, 686-694.

McAlpine, D., Lumsden, C. E., and Acheson, E. D. (1965). Multiple Sclerosis, a Reappraisal, p. 34. Livingstone: Edinburgh.

Mancini, G., Vaerman, J.-P., Carbonara, A. O., and Heremans, J. F. (1964). A single-radial-diffusion method for the immunological quantitation of proteins. In Protides of the Biological Fluids, pp. 370-373. Edited by H. Peeters. Elsevier: Amsterdam.

Putnam, T. J. (1935). Studies in multiple sclerosis. 4. 'Encephalitis' and sclerotic plaques produced by venular obstruction. Archives of Neurology and Psychiatry, 33, 929940.

Rouser, G., Galli, C., Lieber, F., Blank, M. L., and Privett, O. S. (1964). Analytical fractionation of complex lipid mixtures: DEAE cellulose column chromatography combined with quantitative thin layer chromatography. Journal of the American Oil Chemists' Society, 41, 836-840.

Rouser, G., Kritchevsky, G., Galli, C., and Heller, D. (1965). Determination of polar lipids: quantitative column and thin-layer chromatography. Journal of the American Oil Chemists' Society, 42, 215-227.

Rouser, G., Siakotos, A. N., and Fleischer, S. (1966). Quantitative analysis of phospholipids by thin-layer chromatography and phosphorus analysis of spots. Lipids, 1, 85-86.

Shore, P. A., and Alpers, H. S. (1963). Platelet damage induced in plasma by certain fatty acids. Nature, 200, 13311332.

Thompson, R. H. S. (1966). A biochemical approach to the problem of multiple sclerosis. Proceedings of the Royal Society of Medicine, 59, 269-276.

White, H. B., Jr., and Powell, S. S. (1968). Isolation and analysis of trienoic and tetraenoic fatty acids with complementary thin layer and gas-liquid chromatography. Journal of Chromatography, 32, 451-457.

Wright, H. P., Thompson, R. H. S., and Zilkha, K. J. (1965). Platelet adhesiveness in multiple sclerosis. Lancet, 2, 11091110. 